\title{
A ECOSOFIA COMO PARADIGMA ESTÉTICO: ENFRENTANDO O MAR DE LAMA
}

\author{
ECOSOPHY AS AN AESTHETIC PARADIGM: \\ TO FACE THE SEA OF MUD
}

\begin{abstract}
Resumo: Este artigo resulta de pesquisa bibliográfica na qual abordamos a ecosofia enquanto paradigma estético inserida no contexto dos problemas ecológicos contemporâneos. Trata-se aqui de realizarmos um exercício de pensamento tendo como sustentação epistêmica a filosofia da multiplicidade, deleuzeguattariana; mais especificamente, com a proposta do filósofo Félix Guattari em torno de um paradigma ecosófico desdobrado em três grandes perspectivas ecológicas: a do meio ambiente, a das relações sociais e a da subjetividade humana. Desses constructos depreendem-se pautas socioeducativas que permitem pensar maneiras de se vivenciar as relações do homem com a natureza, com o outro e consigo próprio.
\end{abstract}

Palavras-chave: Ecologia. Ecosofia. Filosofia da educação. Paradigma estético.

\begin{abstract}
This paper is the result of a bibliographic research in which we approached the philosophy as an aesthetic paradigm inserted in the context of contemporary ecological problems. It is a question of carrying out an exercise of thought based on the epistemic support of the philosophy of multiplicity, Deleuze-Guattarian, more specifically with the proposal of the philosopher Félix Guattari around the eco-philosophical paradigm that unfolds in three major ecological perspectives: that of the environment, that of social relations and that of human subjectivity. These constructs reveal socio-educational guidelines that allow for rethinking ways of experiencing man's relations with nature, with others and with himself.
\end{abstract}

Keywords: Ecology. Ecosophy. Philosophy of education. Aesthetic paradigm.

\section{Para citar - (ABNT NBR 6023:2018)}

VITKOWSKI, José Rogério. A ecosofia como paradigma estético: enfrentando o mar de lama. Eccos - Revista Cientifica, São Paulo, n. 53, p. 1-13, e16552, abr./jun. 2020. Disponível em: https://doi.org/10.5585/eccos.n53.16552. 
Este artigo resulta de pesquisa bibliográfica na qual abordamos a ecosofia enquanto paradigma estético-político, no contexto dos problemas ecológicos contemporâneos. A ancoragem epistêmica mais ampla se dá por meio da filosofia da multiplicidade, de autoria dos filósofos Gilles Deleuze e Félix Guattari.

Em linhas gerais, pode-se afirmar que, tanto na versão conjunta quanto no trabalho solo dos autores, a filosofia pode ser compreendida como uma potência do pensamento humano cuja finalidade primordial é a criação de conceitos (DELEUZE; GUATTARI, 1992). Isso significa que os conceitos não estão nem prontos nem acabados. Por meio de uma pedagogia do conceito e de procedimentos de desterritorialização e reterritorialização, é possível pensar filosoficamente (GALLO, 2018). Nesse contexto, pensar não se reduz à ordem da mera abstração, da boa conduta do raciocínio, do cálculo insípido ou da obsessão falso-verdadeiro. Pensar se vincula, antes, à experimentação, ao encontro, aos acontecimentos, às intensidades do sensível.

Especificamente, nos propomos a realizar aqui um exercício de pensamento vinculado ao plano de imanência ecológico, destacando, por uma questão de delimitação, tópicos dos textos de Félix Guattari, “As três ecologias" (2012) e Caosmose (2012b), nos quais o autor enfatiza o desenvolvimento de um paradigma estético para o trato dos problemas ecológicos, que envolvem, imbricadamente, o meio ambiente, a sociabilidade e a subjetividade.

A escrita deste texto intenta se aproximar de uma sugestiva fórmula "deleuzeguattariana", a saber, a fórmula n-1, descrita em Mil Platôs (1995). Ela nos sugere escrever rizomaticamente, rompendo centros, buscando alianças, estabelecendo relações com os conceitos e constructos teóricos da filosofia e, também, com os afetos e perceptos advindos da sensibilidade da arte. Portanto, trata-se aqui de uma tentativa de promover "artistagens", como sugere Corazza (2006), misturas entre os registros filosófico e artístico.

Subdividiremos este texto sob a forma de cenas que buscam retratar os movimentos alinhados ao conceito de ecosofia e às três ecologias propostas por Félix Guattari. Daqui, depreendem-se pautas que, a nosso ver, convidam a repensarmos as relações do homem com a natureza, com o outro e consigo próprio.

Destacamos, ainda, que iniciamos uma primeira leitura dos textos guattarianos citados quando a barragem na cidade de Brumadinho-MG rompeu, provocando uma das maiores catástrofes ecológicas do Brasil. A lama destruidora tomou forma de um mar, o mar-de-lama. A partir das intensidades daqueles acontecimentos, não ficamos indiferentes e fomos motivados a elaborar as tessituras que seguem. 
Cena I - "O Rio? É doce. A vale? Amarga” (DRUMMOND)

Temos acompanhado no Brasil com uma frequência absurda as notícias que envolvem desastres ecológicos: queimadas gigantescas, derramamento de óleo na costa litorânea, contaminação e destruição da natureza, da fauna, da flora, com consequências irremediáveis. Essa dinâmica de empobrecimento ecológico que se estende pelo cotidiano foi captada pelo "Xote ecológico", canção de Luiz Gonzaga:

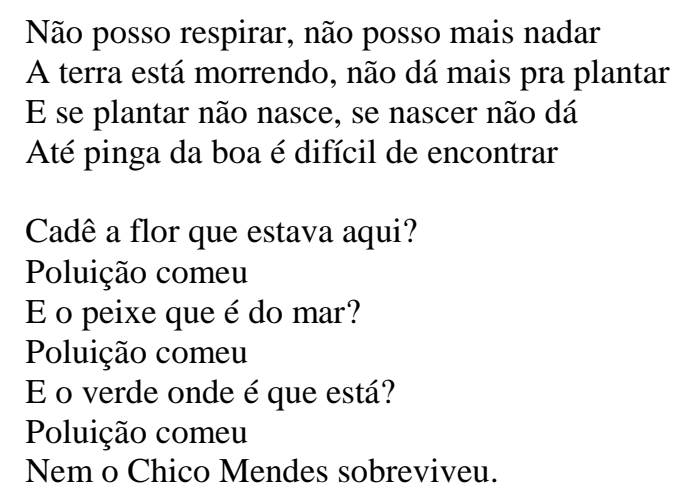

A letra nos lembra singelamente que nossas vidas estão cada vez mais afetadas por toda uma variedade de fenômenos poluidores que expressam o descuido com a natureza, com a vida humana e com aqueles que a defendem. Sim, nem o Chico Mendes sobreviveu. Hoje uma longa lista de nomes se junta ao de Chico Mendes: Irmã Dorothy, Marielle e tantos outros. Ao leitor, acrescentar o nome de ambientalistas, religiosos e uma imensa quantidade de indígenas assassinados covardemente. E, como afirmou a ativista sueca Greta Thunberg: "Os povos indígenas estão sendo literalmente assassinados por tentar proteger as florestas do desmatamento. [...] É vergonhoso que o mundo permaneça calado sobre isso" (THUNBERG, 2019).

De fato, o Brasil é um dos países que lideram o extermínio de defensores da natureza. Não escapa à observação mais elementar o apoio paradoxal e insano dos políticos de plantão, aliados à ganância empresarial, ao propugnar "pseudossoluções" para os conflitos da terra no Brasil. Meio ambiente e vidas humanas continuam sendo destruídas.

A indignação aumenta quando olhamos para a história recente, particularmente, nas tragédias de Mariana, em 2015, e Brumadinho, em 2019. Esses acontecimentos compõem um triste e complexo cenário que demanda vigilância epistêmica traduzida em diferentes linguagens. 
O poeta Carlos Drummond de Andrade, mineiro de Itabira, publicou em 1984 um poema — "Lira Itabirana" - que, de certa maneira, já era uma profecia sobre os crimes ecológicos que ocorreriam nas cidades citadas.

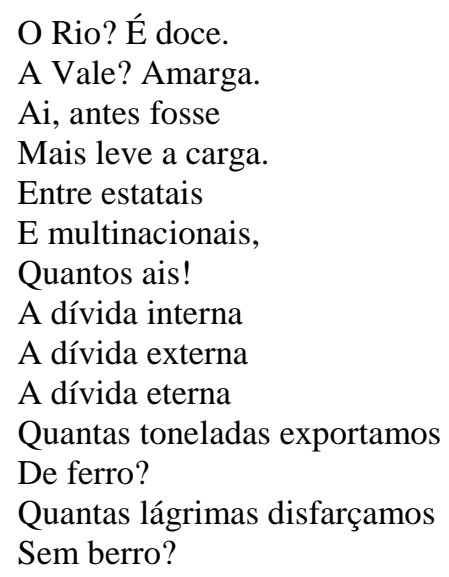

O poeta-profeta, com sua alta sensibilidade, entrevê intuitivamente o pesado fardo que produziu dores incomensuráveis, lamentos indescritíveis, tantos “ais". Desespero e morte compuseram o cenário trágico. Lembremos das centenas de vidas ceifadas e de famílias destruídas. Ao leitor, relembrar e acrescentar os detalhes dos lamentáveis acontecimentos fartamente publicados pelas mídias enquanto rendiam ibope.

De fato, nos lembra Drummond, entre a estatais e multinacionais, a retórica desenvolvimentista se autojustifica e é reconhecida numa espécie de refrão nos meios políticos e empresariais: precisamos pagar as dívidas, buscar o progresso, o desenvolvimento. O discurso que tudo homogeniza com uma racionalidade de cunho eficientista apregoa incessantemente a exploração das riquezas: sejam elas naturais ou do trabalho humano. Os verbos mais empregados por arautos engravatados designam: explorar, exportar, desenvolver. Ficam obliterados os verbos empregar, distribuir, humanizar, preservar, cuidar.

Esse cenário nos remete a pensar mais amplamente as questões socioecológicas.

Cena II - Que será de mim?

De fato, o Brasil convive diuturnamente com efeitos de crises que se sobrepõem e que atingem o meio ambiente e atravessam a existência cotidiana do cidadão. São pesadelos dentro de pesadelos. Novamente, emprestamos o olhar do poeta para Mariana e Brumadinho (MINAS NÃO TEM MAR, 2019): 
Minas não tem mar,

Mas fizeram dois mares de lama nas minas.

Cadê minha casa que estava aqui?

Cadê meu boi, meu cavalo?

Cadê meu cachorro?

Cadê meu pé de mamão?

Meu carrinho de mão?

Cadê meu pé de limão?

Cadê meus livros?

Cadê meu arroz, feijão?

Cadê meu colchão?

Cadê meu pai, minha mãe, meus irmãos?

A lama levou...

A lama levou minha vida

Meus sonhos,

Meu porto seguro,

Meu chão.

Não foi a lama não,

Foi o homem que fez a lama, que jogou Mariana e Brumadinho no chão.

Tingiu de marrom as águas do meu Rio Doce,

Coloriu de terra meu Paraopeba,

Vai tingir meu Velho Chico.

Vai calar a voz dos passarinhos,

Matar os peixes,

Que será de mim?

Quem devolverá tudo que levaram de mim?

(Autor Desconhecido)

Difícil não se emocionar diante desse poema que exprime uma profunda dor, que permanece no peito dos que vivenciaram os trágicos acontecimentos. A perda do boi, do cavalo, do cachorro, da planta, do colchão, da mãe e do irmão nos remete ao mais profundo âmago da tristeza, da desolação, do sofrimento humano.

A sensibilidade do poeta subitamente nos faz ver um paradoxo. Não foi a lama que derrubou Brumadinho e Mariana. Mas o homem que fez a lama. Hoje, por um lado, o país ainda chora os mais de 259 mortos e dezenas de desaparecidos deixados pela avalanche de lama produzida pelo rompimento de uma barragem de rejeitos da mineradora Vale, em Brumadinho. Por outro, uma pergunta indignada emergiu no seio da sociedade brasileira: até quando a negligência de empresas e do poder público continuará custando vidas? A resposta só poderá ser dada por um compromisso eminentemente éticopolítico e estético, sob pena de ingenuamente permanecer em pseudonarrativas ecológicas, pois, como afirma Guattari (2012, p. 24): "Não podemos nos deixar guiar cegamente pelos tecnocratas dos aparelhos de Estado para controlar as evoluções e conjurar os riscos nesses domínios, regidos no essencial pelos princípios da economia de lucro".

Essa afirmação guattariana destaca a cegueira tecnocrática e um dos princípios basilares aceitos pacificamente na economia e nas políticas neoliberais, isto é, o lucro a todo preço; lucro que se transforma em cânone intocável nos meios econômicos, empresariais, gestionários e psicossociais. 
A avidez do lucro torna-se um princípio que se expande permanente e perigosamente; tal qual uma avalanche de lama, não encontra barreiras e passa a tomar conta da psiqué contemporânea. De fato, as subjetividades hoje não estão imunes, ao contrário, são regidas por uma lógica instrumental orquestrada pelos verbos: ter, possuir, dominar, trocar, levar vantagem, lucrar. É fácil perceber como a política dos afetos midiáticos, familiares, grupais, individuais, carece cada dia mais de gratuidade, de relações generosas e solidárias. Quando muito, são produzidos corporativismos de duvidosa condição, nos quais a solidariedade se confunde com assistencialismos, bonomias festivas, protecionismos grupais e de classe, temperados por rituais e religiosidades alienantes.

Cena III - A lama leva nossas vidas, nossos sonhos e nosso chão.

O poema anteriormente citado nos alerta para os perigos da lama provocados pela ação humana. Sim, a lama destruidora em Brumadinho tomou forma de um mar, o mar-de-lama. Por isso mesmo, perigosa e letal. O dicionário indica expressões como: "viver na lama", "tirar da lama".

De fato, a expressão proverbial "mar-de-lama" faz parte de um dos mais poderosos bordões da política brasileira, assinala Rodrigues (2019). Uma espécie de senha que indica a corrupção generalizada e avassaladora. Enquanto metáfora, a lama está fincada na história. $\mathrm{Na}$ tradição colonial em que o Brasil nasceu e se desenvolveu, a lama simboliza o atraso. A urbanização é uma guerra contra ela. Carros de boi, carroças e charretes atolavam na lama; vacas iam para o brejo. "É o carro enguiçado, é a lama, é a lama", cantava Tom Jobim.

Além disso, coube à lama significar pobreza e sujeira, tanto física quanto moral. "Que tristeza prá subir ao mais alto degrau da fama", cantava Clara Nunes, "com uma moral enterrada na lama". O tema é recorrente em um samba de 1953: "se o meu passado foi lama. Hoje quem me difama. Viveu na lama também” (NUNES, 2020).

Ainda que esses sentidos sejam dominantes, a lama pode ser associada a outros aspectos da vida. O banho de lama é uma das mais antigas formas de cura e remonta a culturas milenares. O banho de lama era popularmente usado pelos gregos. Já nos relatos mítico-religiosos, uma força simbólica ímpar brota da terra e água com conotação positiva, pois está associada à criação da vida. Basta relembrar relatos gregos e judaicos nos quais a humanidade é moldada por mãos divinas tendo por matéria-prima algum tipo de barro, de argila. No livro do Gênesis, encontramos o divino Oleiro moldando o barro e nele soprando o seu espírito. Terra, barro, lama também podem ser compreendidos como potência de vida. 
Todavia, no Brasil, com as catástrofes de Mariana e, em versão incomparavelmente mais mortífera e absurda, em Brumadinho:

[A] velha lama brasileira se adensa. Acrescida de milhares e milhares de toneladas de metais venenosos e plenos de desprezo, não se limita a romper as barragens do sentido figurado: soterra qualquer ligação com a vida que pudesse estar no barro. Atraso, sujeira física e moral, tudo isso parece pouco. Nossa lama simboliza a morte (RODRIGUES, 2019).

Estamos enlameados até a alma. Por isso mesmo, além da indignação, urge repensar os antagonismos, os paradoxos que nos assolam na busca de linhas de fuga, saídas alternativas, criativas, como nos sugere Guattari. De acordo com o filósofo: "o novo paradigma estético tem implicações ético-políticas, porque quem fala em criação, fala em responsabilidade da instância criadora em relação à coisa criada, em inflexão de estado de coisas, em bifurcação para além de esquemas pré-estabelecidos" (Guattari, 2012b, p. 123). problemas ecológicos, constatamos com Guattari (2012) que o planeta vive um período de intensas transformações técnico-científicas, mas que engendram concomitantemente intensos desequilíbrios ecológicos que ameaçam a vida de diversas formas e penetram em espaços insuspeitos. Para o autor, os modos de vida contemporâneos individuais e coletivos se desenvolvem no sentido de uma progressiva deterioração. A lama é invasiva e não tem limites. Atingem as redes de parentesco, a vida doméstica, conjugal. Compromete-se a relação da subjetividade com a exterioridade (social, animal, cósmica). O problema é que as formações políticas são incapazes de apreender essa problemática no conjunto de suas implicações. Não se trata de negar esforços pontuais, todavia, prevalecem as abordagens de soluções tecnocráticas de curto fôlego e alcance. Daqui emerge a proposta do filósofo de se promover uma articulação ético-política expressa no conceito de ecosofia, que se desdobra em três registros ecológicos imbricados, a saber: o do meio ambiente, o das relações sociais e o da subjetividade. Nada está isolado!

O autor especifica com clareza o que está em jogo: “é a maneira de viver daqui em diante sobre este planeta, no contexto da aceleração das mutações técnico-científicas e do considerável crescimento demográfico" (GUATTARI, 2012, p. 9). Devido ao contínuo desenvolvimento da informática, o filósofo já compartilhava a tese de que as forças produtivas tornariam disponível uma quantidade cada vez maior do tempo de atividade humana. Ainda que essa afirmação continue polêmica, nos parece interessante propor um duro questionamento: 
tempo disponível para quem e com que finalidade? Ora, as possibilidades nada promissoras para boa parte da humanidade continuam a ser desemprego, marginalidade, doenças, fome, solidão, ociosidade, angústia ou neurose. Nesse contexto, Guattari levanta outro questionamento, que merece ser enfatizado: haveria lugar para criação, para pesquisa, reinvenção do meio ambiente, enriquecimento dos modos de vida e de sensibilidade? Talvez o silêncio ainda seja a resposta.

O autor constata que os problemas ecológicos já não são meramente locais, mas globais, e que "não haverá verdadeira resposta à crise ecológica a não ser em escala planetária e com a condição de que se opere uma autêntica revolução política, social e cultural reorientando os objetivos da produção de bens materiais e imateriais" (GUATTARI, 2012, p. 9). De fato, a economia do lucro e de relações de poder nos leva a dramáticos impasses manifestos na dependência econômica entre os países que dominam o cenário mundial e os menos desenvolvidos. No centro do problema, temos, portanto, o velho conflito entre as nações - que permanece e se arrasta. No primeiro mundo, ocorre a proliferação de tecnologias que provocam riscos graves e irreversíveis ao meio ambiente, como na produção energética por usinas nucleares; no segundo, há uma manutenção de sua pauperização absoluta para manutenção de benefícios e fluxo de materiais e dependência científico-tecnológica. Para Guattari, dois pontos são cruciais nas relações políticas e econômicas entre os países: o imperialismo do mercado mundial, que nivela a um único plano os bens materiais, os bens culturais, as áreas naturais; e as relações sociais e internacionais, que estão sob o domínio de uma máquina policial e militar que fiscaliza, ameaça e até mesmo pune.

Com efeito, a pauperização crescente tem sido expressa em nossos dias nas recentes instabilidades sociopolíticas mundiais; de modo mais próximo, lembramos que no Brasil e na América Latina temos um conjunto de características bastante comuns: agressões ambientais, marginalização de jovens e idosos, desemprego avassalador, fome, doenças, sistemas de proteção social vulneráveis e que penalizam os mais frágeis, violência, drogas. A isso se inclui uma constatação que tem assolado as sociedades contemporâneas: a incapacidade das forças sociais de reagirem. Triste constatação que nos assola no Brasil contemporâneo. Para onde quer que nos voltemos, encontramos um mesmo paradoxo lancinante:

De um lado, o desenvolvimento contínuo de novos meios técnico-científicos potencialmente capazes de resolver as problemáticas ecológicas dominantes e determinar o reequilíbrio das atividades socialmente úteis sobre a superfície do planeta e, de outro lado, a incapacidade das forças sociais organizadas e das formações subjetivas de se apropriarem desses meios para torná-los operativos (GUATTARI, 2012, p. 12). 
O autor percorre ainda uma série de paradoxos e dilemas da condição humana, que se expressam nas relações de trabalho, na exploração infanto-juvenil, no movimento feminista, na desculturalização de comunidades nativas, nas ideologias arcaicas, nas demagogias massificantes. Esses traços molares agravam a crise ecológica contemporânea e demandam, portanto, uma nova perspectiva revolucionária.

Para a revolução apregoada por Guattari, é necessário ir além da produção de bens materiais e das forças visíveis em projetos de grande escala; trata-se conjuntamente de considerarmos ações e atitudes que dizem respeito aos domínios moleculares de sensibilidade, de inteligência e de desejo. Assim, a ecosofia se apresenta e reveste seus fundamentos numa dimensão ético-estética.

Esse paradigma estético enfatiza a produção e recriação da heterogeneidade, que busca encontrar seu potencial de emergência no contexto de um mundo da técnica e da desterritorialização dos valores. A heterogênese é entendida como um processo contínuo de ressingularização, no qual os indivíduos devem se tornar, a um só tempo, solidários e cada vez mais diferentes. Não se trata, pois, de uma operação dialética, destaca o filosófo, porque não há resolução dos contrários, e sim de uma espécie de afirmação de subjetivação parcial que vai produzir efeito também nos conjuntos não humanos. Para o autor, trata-se de questionar se continuamos na finalidade catastrófica da homogênese capitalística dos valores, que impõe uma espécie de padronização dos comportamentos, ou se buscamos, no âmbito da vida cotidiana, as singularidades microscópicas em que se pode recuperar a subjetivação pelo cultivo do dissenso e da produção singular da existência.

Como exemplos de revolução subjetiva ascendente, podem-se citar as mudanças na condição feminina acontecidas em muitas sociedades — ainda que permaneça a exploração do trabalho; as lutas contra o racismo; a construção de um mínimo de territórios existenciais pelos jovens. Esses exemplos ajudam a situar um contexto de ruptura, de descentramento, de multiplicação dos antagonismos e de processos de singularização em que surgem as novas problemáticas ecológicas. Mas, para que esses movimentos produzam mudanças mais profundas na sociedade, é necessário que tenham em mira, a título de objetivo maior, os modos de produção de subjetividade — isto é, de conhecimento, cultura, sensibilidade e sociabilidade.

Em síntese, Guattari propõe, sob a égide do conceito de ecosofia, um conjunto de práticas ecológicas, a saber, a ecologia subjetiva ou mental, a ecologia social e a ecologia do meio ambiente. A mental será levada a reinventar a relação do sujeito com o corpo, com a psique, com a sensibilidade. Trata-se também de procurar antídotos para a uniformização dos modismos, consumismos, propalados pela cultura midiática. A ecosofia social consistirá em 
desenvolver práticas que tendam a modificar e a reinventar maneiras de ser, seja no seio do casal, da família, do contexto urbano ou do trabalho. E a do meio ambiente visa a um novo paradigma no trato com a natureza. É no conjunto dessas frentes heterogêneas, mas que se tocam, se misturam, se embaralham, que deverão articular-se as novas práticas ecológicas.

Para o pensador, a Ecosofia é um modelo prático e especulativo, ético-político e estético, não sendo uma disciplina, mas sim uma simples e eficaz renovação das antigas formas de concepção do ser humano, da sociedade e do meio ambiente. Cabe à ecosofia promover:

\begin{abstract}
Novas práticas sociais, novas práticas estéticas, novas práticas de si na relação com o outro, com o estrangeiro, com o estranho: todo um programa que parecerá bem distante das urgências do momento! E, no entanto, é exatamente na articulação: da subjetividade em estado nascente, do socius em estado mutante, do meio ambiente no ponto em que pode ser reinventado, que estará em jogo a saída das crises maiores de nossa época (GUATTARI, 2012, p. 55).
\end{abstract}

Não se trata aqui de propor um modelo de sociedade pronto para usar, mas de incentivar os processos de ressingularização nos mais diferentes espaços-tempos da existência humana. Por meio deles, conclui o autor, "toda uma catálise da retomada de confiança na humanidade em si mesma está para ser forjada passo a passo e, às vezes, a partir dos meios mais minúsculos" (GUATTARI, 2012, p. 56).

\title{
Cena V-Epílogo
}

À guisa de finalização, apontamos para algumas implicações, inferidas a partir deste texto, que podem transbordar para outros planos de imanência, dentre eles, o educacional. Aliás, a implicação é uma linha constitutiva da filosofia da multiplicidade, na qual as coisas, os acontecimentos, se dobram, se desdobram e se redobram e se implicam.

Um primeiro aspecto a destacar é a força do conceito ecosofia. Nele se condensa um exercício filosófico singular. Nestes tempos difíceis, nos quais a filosofia tem sido desconsiderada, parece-nos importante valorizá-la como um modo de conhecimento ativo, não meramente reflexivo, reprodutivo ou ornamental — mas cuja finalidade é a produção de conceitos, como nos sugerem Deleuze e Guattari (1992).

Ainda em termos estritamente filosóficos, cabe registrar que a noção de ecosofia pode ser compreendida como um desdobramento de outro conceito produzido pela filosofia da multiplicidade, a saber, o conceito de rizoma, apresentado em Mil Platôs (2007). Trata-se de perceber que o regime de conexões ilimitadas que o conceito de ecosofia pode operar pertence a uma mesma lógica não representacional. Já não basta, portanto, isolar o problema ambiental das outras perspectivas da vida, como da sociabilidade, da subjetividade. Tudo está conectado, 
sem que haja um centro privilegiado de hierarquia. Nessa perspectiva, a ecosofia reforça o caráter de heterogeneidade e de multiplicidade. Abre-se assim um horizonte permanente para que rompamos, na educação, com as concepções dualistas e identitárias que separam o homem e a natureza, o econômico do social, a razão e a emoção, a política da ética.

Num olhar mais pedagógico, a ecosofia nos convida, ainda, a nos contrapormos aos modelos educacionais de viés neopositivistas que tomaram força nesses últimos tempos na educação. Sabemos que os espaços de formação acadêmica e da escola, no Brasil, têm sido afetados por forças políticas retrógadas fundadas num direitismo de dúbia condição. Faz-se urgente e necessário o combate ao fascismo cultural que se expande de modo assustador. É evidente que a ecosofia não deve ser apresentada como proposta de modelização ou de prescrições de novas verdades educacionais; seria antitético e descabido. Entretanto, educadores e educandos podem encontrar na ecosofia elementos motivadores para produzir diferenças, desenvolver a desterritorialização de processos educativos cooptados pela máquina de controle. Trata-se aqui de retomar a ideia de vigilância, do "estar à espreita", devir atento ao que acontece; enfim, promover a vigilância epistêmica, traduzida em novas posturas de resistência diante dos mecanismos de controle e de degradação social que habitam a educação.

Nessa perspectiva, a ecosofia não necessita se tornar um programa a ser inserido nas escolas em modelos disciplinares, mas pode permanecer como um horizonte maior, uma fonte epistêmica capaz de produzir e inspirar pesquisas, concepções educacionais, atitudes que promovam singularidades e agenciamentos inusitados, ou seja, micropolíticas de existências. Aliás, assinalamos que a formação de professores parece aqui encontrar uma referência importante para a produção de seus constructos e projetos. Talvez novas trilhas de reencantamento e potencialização da educação possam surgir. Para isso, torna-se fundamental desenvolver, no âmbito da ecologia mental ou da subjetividade, uma nova psicologia capaz de romper o comodismo, os fundamentalismos políticos, religiosos, pedagógicos e, particularmente, a subjetividade contaminada pela indiferença e pela acídia nas relações.

Quanto aos desastres ambientais de Mariana e Brumadinho, eles permanecem como símbolos de nossa pobreza moral, ética. Decorrido mais de um ano, as manchetes midiáticas registram que as famílias das vítimas, particularmente as de Brumadinho, ainda não tiveram as demandas político-sociais e jurídicas atendidas dignamente. Uma legião de órfãos, viúvas, se multiplicou entre os que habitavam a região. Juntem-se a isso as subjetividades despedaçadas pela falta de horizonte. Tomam conta dos noticiários as evasivas cínicas dos responsáveis pela barragem. O direito cambaleia, a justiça sangra. E o rio Paraobeba, agredido criminosamente, 
ainda não se refez dos efeitos da lama. A natureza chora. O mar de lama continua a produzir seus efeitos. Tristes trópicos.

Nesse contexto, desejamos que a escola seja um lugar da memória. Mariana e Brumadinho tornaram-se acontecimentos centrais, ícones que expressam a gravíssima crise ecológica, que não pode ser esquecida da memória histórico-social e política de nosso país. Uma subjetividade ecosófica, a nosso ver, deve permanecer em sintonia fina com uma espécie de "mística" que provém dos deserdados da terra; daqueles que sofrem todo tipo de violência e que passam a viver à margem do grande sistema.

Por fim, desejamos que o conceito de ecosofia venha a ser desterritorializado nos múltiplos espaços-tempos educacionais e que nos leve a problematizar criativamente a sociabilidade humana, os mecanismos de subjetivação e tudo o que se refere ao meio ambiente, imbricadamente. Assim compreendida, a ecosofia torna-se um novo ethos a ser pensado, cultivado, desenvolvido nos diferentes mares de lama da existência humana.

\section{Referências}

CORAZZA. Sandra Mara. Artistagens: Filosofia da Diferença e educação. São Paulo. Autêntica, 2006.

DELEUZE, Gilles; GUATTARI, Félix. O que é a filosofia? Tradução de Bento Prado Jr. e Alberto Alonso Munoz. Rio de Janeiro: Ed 34, 1992.

DELEUZE, Gilles; GUATTARI, Félix. Mil Platôs: Capitalismo e esquizofrenia. Tradução de Ana Lúcia de Oliveira e Lúcia Cláudia Leão. São Paulo: Ed. 34, 1995. v. 2.

DRUMOND DE ANDRADE, Carlos. Lira Itabirana. Disponível em https://centroloyola.org.br/revista/bagagem/um-poema/833-lira-itabirana. Acesso em: 31 jan. 2020 .

GUATTARI, Félix. As três ecologias. Tradução de Maria Cristina F. Bittencourt; revisão da tradução por Suely Rolnik. 21 ed. Campinas: Papirus, 2012.

GUATTARI, Félix. Caosmose: Um novo paradigma estético. Tradução de Ana Lúcia de Oliveira e Lúcia Cláudia Leão. São Paulo: Editora 34, 2012 b.

GALLO, Silvio. Deleuze \& a Educação. Belo Horizonte. Autêntica, 2008.

GONZAGA, Luiz. Xote ambiental. Canal sua letra. Disponível em:

https://www.youtube.com/watch?v=2ym-iFuhDJM. Acesso em: 30 jan. 2020.

CORREIO BRAZILIENSE. Poesia sobre Brumadinho na voz de Cid Moreira viraliza; veja o vídeo. Correio Braziliense, Brasília, 29/01/2019. Disponível em:

https://www.correiobraziliense.com.br/app/noticia/brasil/2019/01/29/interna- 
brasil,733994/poesia-sobre-brumadinho-na-voz-de-cid-moreira-viraliza-veja-o-video.shtml. Acesso em: 7 nov. 2019.

NUNES, Clara. Lama. Letras.mus. Composição de Mauro Duarte. Disponível em: https://www.letras.mus.br/clara-nunes/118689/. Acesso em: 31 jan. 2020.

RODRIGUES, Sérgio. Com a lama na alma. Folha de São Paulo, São Paulo, 31/01/2019. Disponível em: https://www1.folha.uol.com.br/colunas/sergio-rodrigues/2019/01/com-alama-na-alma.shtml. Acesso em: 31 jan. 2020.

THUNBERG, Greta. Índios são mortos por tentarem proteger floresta. Metrópoles. Disponível em: https://www.metropoles.com/brasil/meio-ambiente-brasil/greta-thunbergindios-sao-mortos-por-tentarem-proteger-floresta. Acesso em: 31 jan. 2020. 